Vittalle - Revista de Ciências da Saúde 29 n. 2 (2017) 11-22

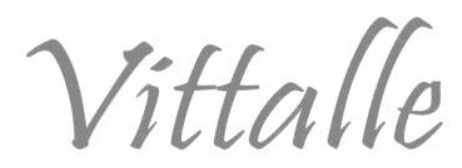

\title{
Pesquisa sobre sexualidade e gravidez na adolescência: uma reflexão acerca da importância da articulação do conhecimento através da participação ativa dos estudantes
}

\author{
Nayara Campos da Cunha*a ${ }^{*}$, Izabella Scalabrini Saraiva ${ }^{a}$, \\ Marcelo Diniz Monteiro de Barros ${ }^{\mathrm{a}}$
}

anstituto de Ciências Biológicas e da Saúde, Pontifícia Universidade Católica de Minas Gerais, Betim, Minas Gerais, Brasil.

Histórico do Artigo

Recebido em: 05/07/2017

Aceito em: 16/09/2017

Palavras-chave orientação sexual educação temas transversais

Keywords sexual orientation education cross-cutting themes

\section{RESUMO}

A orientação sexual permite a transmissão de conhecimentos que fazem parte do ser, aplicando a esses os valores necessários para o autoconhecimento, respeito e dignidade dos estudantes. Entende-se a relevância desse assunto com outros saberes construídos pela sociedade e torna-se fundamental a disseminação correta de informações. Dessa forma, acredita-se que a abordagem da sexualidade configura-se como um assunto imprescindível dentro das escolas para a construção e desenvolvimento humano. Para isso, foi elaborado um projeto sobre sexualidade numa escola da rede estadual de ensino, objetivando a participação ativa dos educandos a partir da aplicação de um questionário para conhecer a realidade dos participantes do projeto. Com auxílio dos dados coletados, ministrou-se uma aula teóricoprática com o auxílio de slides, vídeos, modelos anatômicos e caixa de contraceptivos. Posteriormente, desenvolveu-se com os alunos um trabalho de investigação sobre educação sexual que foi apresentado no formato de uma feira de ciências para a comunidade escolar. Percebe-se que o presente trabalho foi bem sucedido em transpor os conhecimentos acerca da sexualidade, além de promover a participação dos discentes no próprio aprendizado.

Research on sexuality and adolescent pregnancy: a reflection on the importance of coordination of knowledge through active participation of students

\begin{abstract}
Sexual orientation allows the transmission of knowledge that is part of the human, applying to them the values necessary for the self-knowledge, respect and dignity of the students. It is understood the relevance of this subject with other knowledge built by the society and it becomes fundamental the correct dissemination of information. In this way, it is believed that the approach of sexuality appears as an essential subject in schools for building and human development. For this, a project on sexuality was elaborated in a school of the state education network aiming at the active participation of the learners from the application of a questionnaire to know the reality of the participants of the project. Using the data collected, a theoretical-practical class was given with the aid of slides, videos, anatomical models and a contraceptive box. Subsequently, a research work on sex education was developed with the students that was presented in the format of a science fair for the school community. It can be noticed that the present work was successful in transposing the knowledge about sexuality, besides promoting the participation of the students in the own learning.
\end{abstract}




\title{
1. Introdução
}

O debate sobre os direitos sexuais e direitos reprodutivos está inserido em uma das áreas de atuação prioritárias da Atenção Básica em saúde, que é a saúde sexual e reprodutiva (1). Educar sobre esse tópico é uma responsabilidade social, entretanto recai quase exclusivamente sob a escola dispor de informações para o acesso a uma sexualidade saudável para os jovens (2). Esse fenômeno pode ser compreendido a partir do trecho do artigo Beraldo (2003) (3).

\begin{abstract}
A maior parte dos adolescentes passam seu tempo na escola onde começam a se sociabilizar, aflorando sua sexualidade devido ao desenvolvimento corporal gerado pelos hormônios. A escola é o ambiente onde a interação com o mundo ao redor e com as pessoas que o cercam acontece. Depois do ambiente familiar é a escola que complementa a educação dada pela família onde são abordados temas mais complexos que no dia-a-dia não são ensinados e aprendidos (3).
\end{abstract}

Dessa forma, a temática Sexualidade foi inserida junto aos temas transversais dos Parâmetros Curriculares Nacionais (PCN), sendo definido pelo Ministério da Educação e Cultura (MEC) como algo inerente, que se manifesta desde o momento do nascimento até a morte, de formas diferentes a cada etapa do desenvolvimento (4). Como esse tema está diretamente ligado com o autoconhecimento, respeito e saúde dos indivíduos, é essencial o papel dos educadores na orientação sexual dos jovens durante a trajetória escolar. A Base Nacional Comum Curricular (BNCC) também alerta os profissionais da educação a trabalhar eixos inter/transdiplinares para formação dos discentes:

\begin{abstract}
Cabe aos sistemas e redes de ensino, assim como às escolas, em suas respectivas esferas de autonomia e competência, incorporar aos currículos e às propostas pedagógicas a abordagem de temas contemporâneos que afetam a vida humana em escala local, regional e global, preferencialmente de forma transversal e integradora (...) bem como saúde, sexualidade, vida familiar e social, educação para o consumo, educação financeira e fiscal, trabalho, ciência e tecnologia e diversidade cultural (5).
\end{abstract}

Sexo, sexualidade, educação sexual, preconceitos, discriminações sexuais, doenças sexualmente transmissíveis, gravidez precoce são apenas algumas das questões que recorrentemente são acionadas ao se falar em juventude. A sexualidade consiste em uma importante dimensão que atua na condução das condutas juvenis, a qual se articula também às questões de gênero e de subjetivação (6).

O papel da escola na educação sexual pode ser entendido como:

\begin{abstract}
Uma ação coletiva, transdisciplinar e problematizadora das representações e significados sociais sobre assuntos como a construção da corporiedade, a construção da identidade de gênero, famílias, masturbação, responsabilidades, relações sexuais, violência, tolerância, respeito, diversidade, papéis sociais de mulheres e homens, adolescência, comportamentos de riscos, DST, religiosidade (que é diferente de religião, no seu sentido institucional), valores, dignidade, etc...(7).
\end{abstract}

Nesse viés, pode-se inferir que a escola deve agir como uma ponte de conhecimentos acerca da sexualidade em sua abrangência, objetivando trabalhar coletivamente com as diferenças (as diversas formas de manifestar a sexualidade) e o respeito (aceitação a si mesmo e ao próximo). Para atender às propostas dos PCNs sobre orientação sexual, os 
programas devem ser organizados em torno de três eixos norteadores: "Corpo: matriz da sexualidade", "Relações de gênero" e "Prevenção de doenças sexualmente transmissíveis/AIDS" (8).

Dados alarmantes são apresentados sobre os riscos da gestação nessa faixa etária:

\begin{abstract}
A gravidez neste grupo populacional vem sendo considerada, em alguns países, problema de saúde pública [...] Existem referências a maior incidência de anemia materna, doença hipertensiva específica da gravidez, desproporção céfalo-pélvica, infecção urinária, prematuridade, placenta prévia, baixo peso ao nascer, sofrimento fetal agudo intra-parto, complicações no parto (lesões no canal de parto e hemorragias) e puerpério (endometrite, infecções, deiscência de incisões, dificuldade para amamentar, entre outros). [...] Têm sido citados também efeitos negativos na qualidade de vida das jovens que engravidam, com prejuízo no seu crescimento pessoal e profissional. 53\% das adolescentes que engravidam completam o segundo grau, enquanto que, entre as adolescentes que não engravidam, essa cifra corresponde a 95\% (9).
\end{abstract}

A ocorrência de adolescentes grávidas na comunidade foi um dos motivadores desta intervenção. Segundo informações do corpo pedagógico da escola, no período de execução deste trabalho havia três alunas grávidas e o problema de abandono do curso por alunas gestantes já havia sido relatado dentro da instituição.

Entretanto, além de "o que falar?" o "como falar?" precisa e deve ser discutido. Abordar o tema sexualidade, por si só, já é um desafio, pois são inúmeras resistências, tanto para o educador que precisa revisar conceitos, superar preconceitos e estereótipos, quanto para os alunos, principalmente as meninas, que muitas vezes consideram esse assunto um tabu.

Tais orientações demandaram ações específicas na intervenção docente, seja na participação e promoção de debates, na qualificação de estudos específicos e na elaboração de estratégias didático-pedagógicas que colocaram em cena as diferenças e a pluralidade humanas, produzindo e reafirmando conhecimentos e orientações que focaram uma educação voltada para a diversidade(10).

Vários autores afirmam que, para o ensino da orientação sexual, os professores costumam utilizar palestras com profissionais da saúde. As metodologias orientadas pelo discurso médico-biológico cumprem a função de reger a sexualidade, através de conceitos, explicações e modos de disciplinarização, presentes na organização curricular. Porém, a sexualidade vai além de estudos conceituais anatômicos. Também é importante debater sobre as mudanças, as relações de gênero, o respeito a si mesmo e ao outro e à diversidade de crenças, valores e expressões culturais, a superação de tabus e preconceitos $(7,4)$.

Palestras programadas com a intenção de limitar-se à pura informação, descontextualizadas do cotidiano do educando, transmitidas como um processo não planejado e sem a interferência dos jovens, fatalmente se tornarão alvo de opiniões desfavoráveis e até depreciativas, pela escassez de coerência e lógica (7). Pensando dessa forma, procurar entender primeiramente quais são as "ânsias" dos estudantes acerca do tema antes de elaborar uma proposta de intervenção, permite ao educador compreender como direcionar sua aula, adequando-a diretamente ao público alvo.

Além disso, a promoção de um conhecimento embasado na epistemologia construtivista é muito mais abrangente do que o senso comum estabelece, ou seja, objeto não é somente o percebido pelos sentidos, mas, também, tudo o que é criado pelo sujeito, seja na relação com o manipulável, seja nas relações estabelecidas entre abstrações (11). As metodologias vêm sendo amplamente discutidas por diversos autores. A prática educativa não se limita à transmissão e à apreensão de conhecimentos, fazendo-se 
necessário criar um ambiente propício para a assimilação das informações, buscando a participação colaborada entre indivíduos, proporcionando a troca de conhecimento entre alunos e professores $(12,13)$.

O presente trabalho pesquisou, utilizando o questionário como instrumento de coleta de dados, a situação dos adolescentes de uma escola no município de Betim, MG, a respeito do tema sexualidade. A partir das informações extraídas, buscou-se orientar e criar iniciativas com a participação dos próprios alunos para colocar em discussão a temática para todo o corpo estudantil.

\section{Metodologia}

A presente pesquisa foi executada durante a disciplina Estágio Supervisionado I Licenciatura, nos meses de Abril a Junho de 2015, numa escola estadual de bairro, situada no município de Betim, que atende alunos de classe média baixa e baixa. $\mathrm{O}$ tema a ser trabalhado foi proposto pelo próprio corpo pedagógico da escola, uma vez que era perceptível o crescente número de namoros e adolescentes grávidas que frequentavam a escola. Assim, foi elaborado o projeto "Sexualidade e Gravidez na adolescência" em conjunto com duas professoras de Biologia dos turnos da manhã e do turno da tarde. Foram escolhidas quatro turmas, duas de $1^{\circ}$ ano e duas de $2^{\circ}$ ano, todas do Ensino Médio, totalizando 125 alunos.

Quadro 1. Projeto sexualidade e gravidez na adolescência e suas respectivas etapas.

\begin{tabular}{|c|c|c|c|}
\hline \multicolumn{4}{|c|}{ Sexualidade e Gravidez na adolescência } \\
\hline 1 Etapa & $\begin{array}{l}\text { Questionário } \\
\text { (Anexo 1) }\end{array}$ & & \\
\hline 2 Etapa & $\begin{array}{l}\text { Aula expositiva } \\
\text { Teórico/prática }\end{array}$ & & \\
\hline \multirow[t]{8}{*}{3 Etapa } & \multirow{8}{*}{$\begin{array}{c}\text { Trabalho } \\
\text { expositivo: FEIRA } \\
\text { DE } \\
\text { SEXUALIDADE }\end{array}$} & $\begin{array}{c}\text { Sistema Reprodutor } \\
\text { Feminino e Masculino }\end{array}$ & $\begin{array}{l}\text { Varal de modelos didáticos - Para demonstrar os órgãos e } \\
\text { identificar as estruturas. } \\
\text { Desenho dos modelos - Com o nome dos órgãos. }\end{array}$ \\
\hline & & $\begin{array}{l}\text { Doenças Sexualmente } \\
\text { Transmissíveis }\end{array}$ & $\begin{array}{l}\text { Exposição de DST's - Varal de fotos com a imagem da doença e a } \\
\text { explicação. } \\
\text { Folheto sobre a importância do uso de preservativos e a vacina } \\
\text { HPV. }\end{array}$ \\
\hline & & $\begin{array}{c}\text { Métodos } \\
\text { Contraceptivos }\end{array}$ & $\begin{array}{l}\text { Cartaz de colagem dos métodos - Colagem dos métodos com nome } \\
\text { de cada um deles, junto de uma breve explicação. No final foi } \\
\text { apresentado um site para consultas. } \\
\text { http://www.brasil.gov.br/saude/2011/09/inform-se-sobre-como- } \\
\text { funcionam-oito-metodos-anticoncepcionais }>\end{array}$ \\
\hline & & $\begin{array}{l}\text { Gravidez na } \\
\text { adolescência }\end{array}$ & $\begin{array}{l}\text { Varal de fotos - Com fotos de mães adolescentes, de problemas } \\
\text { sociais que podem ser acarretados pela gravidez na adolescência. } \\
\text { Entrevista - Conversaram com uma mãe adolescente (ou futura } \\
\text { mamãe), perguntando quais são as dificuldades e o lado de ser mãe } \\
\text { e o que ela espera para o futuro dela e da criança. }\end{array}$ \\
\hline & & Sexualidade na Mídia & $\begin{array}{l}\text { Pesquisa - Os aluno deverá avaliar os programas que abordam } \\
\text { sexualidade e expor os mesmos em forma de cartaz ou varal. } \\
\text { Teatro - Abordando a sexualidade exacerbada na mídia (Televisão, } \\
\text { revistas, jornais, rádio). }\end{array}$ \\
\hline & & $\begin{array}{l}\text { Sexualidade na } \\
\text { música }\end{array}$ & $\begin{array}{l}\text { Paródia da música "Aquarela" de Toquinho - Falando sobre a } \\
\text { sexualidade. } \\
\text { Varal - com trechos de letras que abordem sexualidade, com o } \\
\text { nome do cantor, nome da música e a idade do cantor. }\end{array}$ \\
\hline & & $\begin{array}{l}\text { Sexualidade em Redes } \\
\text { sociais }\end{array}$ & $\begin{array}{l}\text { Relatos - contando mau uso das redes sociais que geraram } \\
\text { polêmicas. } \\
\text { Teatro - abordando a sexualidade nas redes sociais. }\end{array}$ \\
\hline & & Puberdade & $\begin{array}{l}\text { Poemas ou Paródia - Contando como é essa fase e/ou falando das } \\
\text { mudanças que ocorrem durante essa época. } \\
\text { Cartaz com colagens - com imagens e palavras que retratem essa } \\
\text { fase. }\end{array}$ \\
\hline
\end{tabular}

O projeto consistiu em três etapas: a primeira consistiu na aplicação de um questionário para conhecer a real situação dos alunos da escola; num segundo momento, 
com auxílio dos dados coletados, foi ministrada a aula teórico-prática a partir de slides, vídeos, modelos anatômicos e caixa com contraceptivos; e, posteriormente, desenvolveu-se com os alunos um trabalho sobre educação sexual com oito temas dispostos nas quatro turmas em que a presente pesquisa foi realizada, como descrito no quadro 1.

O questionário foi aplicado durante uma aula de Biologia, nos dois turnos trabalhados. Antes da entrega destes, foi feita uma pequena apresentação do projeto e uma explicação da motivação para aplicação do questionário. O material consistia em 10 questões de múltipla escolha e questões abertas (anexo 1), que visavam investigar o conhecimento do público alvo sobre o tema. Posteriormente, os dados foram contabilizados e dispostos em forma de gráficos e porcentagens, para que fossem conhecidos os temas que deveriam ter maior enfoque durante a aula expositiva.

A proposta interventiva foi ministrada durante duas aulas de Biologia, um dia para anatomia dos sistemas reprodutor feminino e masculino, métodos contraceptivos e doenças sexualmente transmissíveis e outra para trabalhar gravidez na adolescência, autoconhecimento e respeito. Para elaboração das aulas, foi utilizado projetor multimídia e apresentação de slides; vídeos intitulados: "Garota do Carnaval", do canal Parafernalha (14), que apresenta, de forma divertida, uma garota durante as festividades que examina um provável parceiro para se proteger de DST's, ainda o trecho do documentário "Meninas" do Cineluz Produções (15), que apresenta a vida diária de mães adolescentes e suas relações com a família e parceiros diante da situação de gravidez; modelos anatômicos que foram emprestados pela PUC Minas; uma caixa de contraceptivos para demonstração da utilização dos métodos e roda de conversa para debater os temas.

Posteriormente, foi dividida cada uma das salas em dois grupos para elaboração de uma feira de sexualidade, e cada grupo possuía dois líderes que foram escolhidos pelas professoras, de acordo com a pontuação de Biologia do último bimestre, para que todos os grupos possuíssem alunos destaque na disciplina e ficasse o mais homogêneo possível. Os temas foram sorteados aleatoriamente para não haver impasse ou privilegiados, e cada grupo teve duas semanas para elaboração dos trabalhos. Durante esse período, houve tutoria dos líderes com os graduandos participantes da pesquisa, visando auxiliar na construção dos materiais que seriam apresentados para os demais membros do corpo discente. Antes da apresentação para a escola, os alunos apresentaram os materiais para os graduandos e professoras, para que estes fizessem suas considerações sobre os materiais e a postura dos alunos.

Os trabalhos foram expostos durante um recreio prolongado, e as várias formas de apresentação constam no quadro 1 . Os alunos tiveram acesso às salas de aulas do primeiro piso, ao rádio da escola para apresentação de paródias e teatros, painéis pela escola para colar cartazes, bancadas para exposição de relatos e imagens, varal de fotos expostas pelas pilastras. Os alunos participantes também tiveram a oportunidade de ouvir e visitar os trabalhos dos demais grupos, desde que não deixassem seus respectivos trabalhos sozinhos.

A Resolução do Conselho Nacional de Saúde / Comissão Nacional de Ética em Pesquisa, de 2016 reconhece a importância dos Termos de Consentimentos Livres e Esclarecidos (TCLEs) e dos Comitês de Ética, mas registra a não necessidade da elaboração de TCLEs e das submissões aos Comitês de Ética, para questionários como o elaborado no presente estudo, no viés das Ciências Humanas e Sociais (16).

\section{Resultados e discussão}


Os resultados da pesquisa obtidos pelos questionários de 125 participantes registraram as contribuições de 66 meninas, 57 meninos e 2 alunos que não assinalaram o gênero. Apenas durante a correção se percebeu a controvérsia que a questão de gênero poderia causar. Na puberdade, o adolescente está sob intensas transformações estimuladas pela ação hormonal, dentre outras alterações biológicas as quais propiciam uma série de eventos psicológicos que culminam na aquisição de sua identidade sexual (17). Dessa forma, é possível que determinados indivíduos ainda não tenham adquirido esse autoconhecimento, ou simplesmente não se encaixam entre os gêneros dispostos.

Do total, 53 (representando $42,4 \%$ do total de alunos de ambos os sexos) já tiveram relações sexuais, 22 meninas (33,3\% do número total de meninas), e 31 meninos $(54,3 \%$ do número total de meninos). A idade média da primeira relação sexual ocorreu aos 14,9 anos de idade. A iniciação sexual precoce é um comportamento de risco, pois o adolescente exposto a essa situação terá uma chance maior de aumentar o número de parceiros sexuais durante a vida, até que o mesmo faça opção por relações monogâmicas estáveis e, quanto maior o número de parceiros sexuais, maior a chance de exposição a alguma DST (18). O início da vida sexual aos 8 e 10 anos demonstrados no gráfico 1, acarretou um alarde e motivou a abordagem do abuso. O abuso e a exploração sexual de crianças vêm se tornando um tipo de maus-tratos difundido na sociedade [...] e, observase um "despreparo generalizado" envolvendo desde os profissionais da área da saúde a educadores e instituições escolares em manejar e tratar adequadamente os casos surgidos. Dentre os muitos efeitos que esses abusos podem causar, é possível listar: depressão, comportamento autodestrutivo, ansiedade, sentimentos de isolamento e estigmatização, baixa autoestima e abuso de substâncias. (19)

Gráfico 1. Idade da primeira relação sexual dos alunos.

\section{Idade da primeira relação sexual dos alunos}

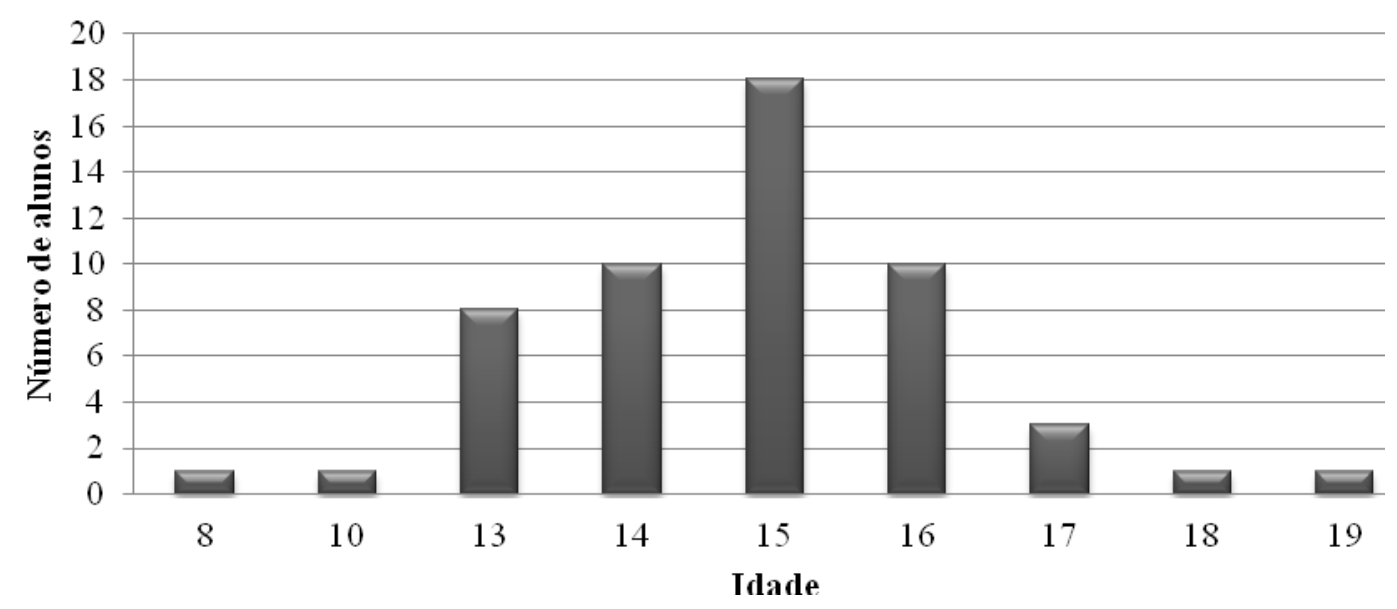

Do total de alunos, $34 \%$ afirmaram usar algum tipo de método contraceptivo, enquanto 43\% não utilizam. Percebeu-se que algumas garotas que não haviam tido relações sexuais haviam marcado que utilizavam a pílula anticoncepcional. Elas são consideradas como benéficas na prevenção de tumores ginecológicos nos ovários e no endométrio, e protegem as mulheres por longos anos, mesmo depois de encerrarem seu 
uso (20). O dado de $23 \%$ dos alunos que não responderam em grande parte são alunos que não conheciam o que significava "métodos contraceptivos" e, por isso, deixaram em branco. Essa informação demonstra a carência de conhecimentos pelos quais os alunos estão acometidos.

Dentre os contraceptivos listados pelos alunos, a camisinha foi o método mais citado, correspondendo a $67 \%$ dos métodos utilizados, seguido da pílula do dia seguinte e da pílula anticoncepcional com 16,4\% e 13,9\%, respectivamente (gráfico 2). O alarmante número de alunos que já utilizaram a pílula do dia seguinte incentivou a ênfase de seus riscos durante as palestras, uma vez que demonstra uma falta de planejamento e, principalmente, um grande desrespeito para com a vida.

Gráfico 2. Métodos contraceptivos utilizados pelos alunos.

\section{Uso do tipo de método contraceptivo}

Uso do tipo de método contraceptivo

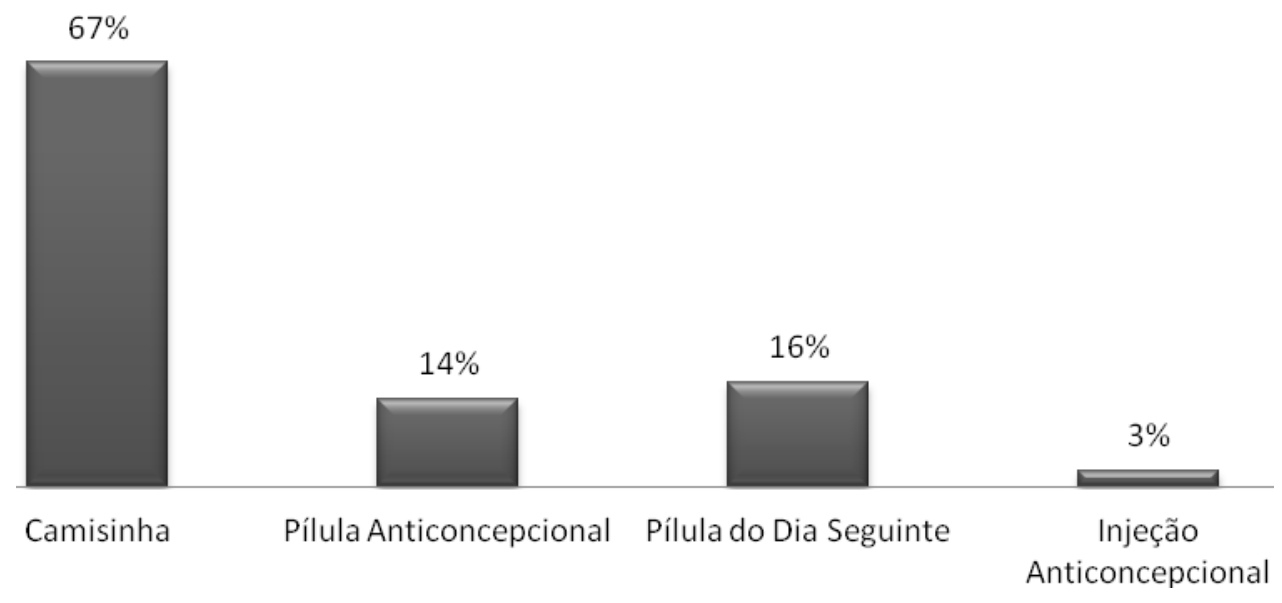

Outra informação importante analisada durante a pesquisa foram as fontes de conhecimento da sexualidade (gráfico 3). Em uma pesquisa acerca dos diálogos sobre a sexualidade entre os familiares de adolescentes grávidas, foi constatada a abordagem por recordações da vivência familiar dos tempos de juventude. Segundo os autores, os pais estabelecem com suas filhas mensagens que se confundem na ambiguidade entre querer orientar, mas temer incentivar a prática sexual (21).

Sabe-se que é essencial que os pais auxiliem de maneira consciente na vivência, gênese e evolução do conhecimento sobre a sexualidade, logo que a família faz parte do processo de formação da sexualidade de seus filhos, o diálogo aberto e sem preconceitos entre pais e filhos é o melhor caminho para a construção da sexualidade das crianças (22).

Sendo a escola um local de aprendizagem e a orientação sexual um tema transversal que deve ser trabalhado interdisciplinarmente dentro da escola, é alarmante perceber que os alunos buscam mais informações sobre o assunto na televisão. A sexualidade está presente em nossa vida desde o momento em que nascemos até a nossa morte. A educação acontece constantemente, seja em casa, pela mídia, assistindo-se televisão, lendo-se revistas e jornais, seja via internet (7). Nesse caso, se a instituição escolar se omite, deliberadamente, em relação a tudo o que se refere ao sexo, essa atitude refletese na formação dos escolares, levando-os a considerar que sexo é alguma coisa secreta, 
é um assunto que não cabe dentro da escola ou, talvez, seja algo vergonhoso sobre o qual não se deve falar.

Nas quatro salas em que o questionário foi aplicado, 97\% dos alunos não possuem filhos, 3\% afirmaram possuir. A gravidez neste grupo populacional vem sendo considerada, em alguns países, problema de saúde pública, uma vez que pode acarretar complicações obstétricas, com repercussões para a mãe e o recém-nascido, bem como problemas psicossociais e econômicos (9). Apesar de o percentual não ser tão grande, considerando o número de alunos com a vida sexual ativa e sua faixa etária, considerouse de grande importância a abordagem do tema durante as palestras.

Gráfico 3. Meios utilizados pelos alunos para se informarem sobre sexualidade.

\section{Principais fontes de informação dos alunos sobre sexualidade}

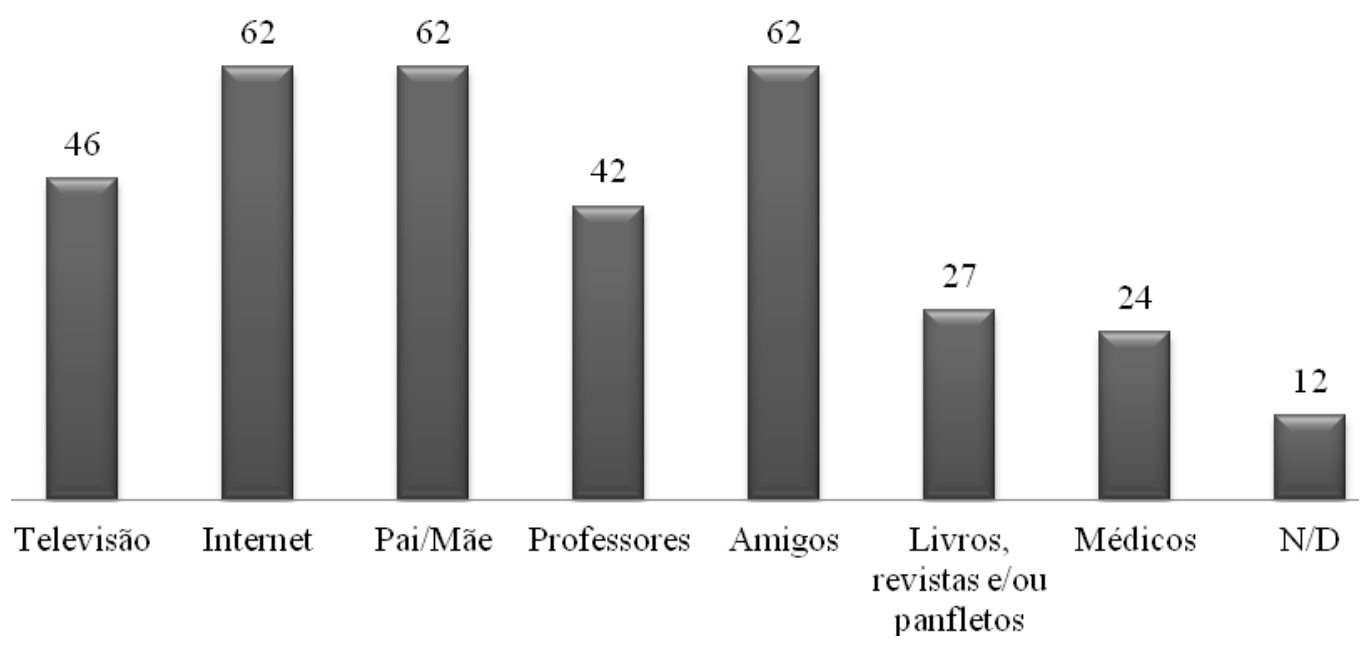

Sobre o conhecimento acerca de doenças sexualmente transmissíveis, 56\% dos alunos souberam dar um exemplo correto, sendo o HIV/AIDS o mais citado pelos alunos.

Sobre as questões a respeito dos órgãos do sistema reprodutor, apenas $32 \%$ acertaram corretamente a função dos testículos e 19,2\% acertaram a função correta do útero. É preocupante o fato de os alunos não conhecerem o próprio corpo.

A última questão do questionário instigava os alunos a descrever suas dúvidas acerca do assunto sexualidade. Dentre as muitas dúvidas apresentadas, destacam-se: a possibilidade de se manter relações durante a gravidez, hermafroditismo, a possibilidade de a ingestão de sêmen fazer mal a saúde, atraso da menstruação, uso e efeitos colaterais dos métodos contraceptivos e proteção contra doenças sexualmente transmissíveis.

Durante as aulas, foi possível estabelecer com os alunos diversos diálogos, respondendo a dúvidas e quebrando tabus e estereótipos do senso comum. Além disso, os diversos recursos utilizados para ministrar as aulas aumentaram a dinâmica de ensino, possibilitando momentos para ouvir as explicações, se assistir vídeos, para questionar, para manusear os modelos anatômicos entre outras atividades, permitindo um aprendizado colaborado e significativo entre os participantes. A escola que se deseja deve ter uma visão integrada das experiências vividas pelos alunos, buscando desenvolver o prazer pelo conhecimento. É necessário que ela reconheça que desempenha um papel importante na educação para uma sexualidade ligada à vida, à 
saúde, ao prazer e ao bem-estar, que integra as diversas dimensões do ser humano envolvidas nesse aspecto (4).

Os trabalhos apresentados na feira de sexualidade foram assistidos pelos demais alunos da escola e pelos docentes. Os alunos utilizaram de criatividade e, para chamar atenção do público em questão, e, dentre as atrações, destacaram-se: teatro mudo para a sinalização do cyber bullying, exibição da canção "Amor e Sexo", composta por Rita Lee e Roberto de Carvalho, para discutir a sexualidade presente na música, a paródia da música "Aquarela" de Toquinho, para discutir sobre a puberdade, folhetos informativos sobre HIV e a vacinação do HPV.

Uma feira de ensino é também fonte geradora de protagonismo juvenil, pois os alunos acabam realizando denúncias sociais e ambientais ou orientando o público sobre como atuar frente a problemas que podem ser solucionados, utilizando o conhecimento científico e tecnológico estudado por eles (23).

O desempenho dos alunos para apresentar um conteúdo de qualidade para o público escolar, o interesse recebido pelo corpo discente, os elogios recebidos aos grupos pela criatividade e compromisso, a experiência de participação de uma feira de ensino pelos próprios alunos, que registraram que a feira auxiliou na promoção de oralidade e a autonomia para construção de conhecimento foram considerados os pontos positivos da elaboração da feira de sexualidade. Como pontos negativos foi apontada a imaturidade de alguns alunos para ouvir sobre o tema, a falta de apoio para resolução de problemas e a organização final da feira, como, por exemplo, ajudar os grupos a montar seus stands.

Complementarmente, o ensino de ciências vem assumindo, dentre muitas de suas atuações, o importante compromisso de familiarizar-se cada vez mais com o conhecimento de seus alunos e dos demais sujeitos da comunidade em que as escolas estão inseridas, ajudando-os a intervir conscientemente nos problemas com os quais são confrontados (24).

O núcleo da epistemologia construtivista situa-se na ação do sujeito sobre o objeto, sendo ambos transformados durante a relação que estabelecem, tornando necessário o efeito das experiências, ou seja, da ação nos objetos para um ganho cognitivo na aprendizagem dos discentes (11). Dessa forma, a feira de sexualidade auxiliou na disseminação de conhecimentos sobre a sexualidade, possibilitando a participação colaborativa entre os estudantes e a investigação e resolução de problemas sociais pelos próprios educandos.

\section{Considerações finais}

A aplicação dos questionários antes das aulas teóricas possibilitou um maior posicionamento dos alunos a respeito do que gostariam de debater dentro do conteúdo de sexualidade, fornecendo ao educador um direcionamento de quais fatores dar ênfase, para uma orientação sexual completa e saudável aos seus discentes.

Sabe-se que a elaboração de feiras de ensino/ciências possibilitam aos educandos o aprimoramento do trabalho em equipe, conhecimento e oralidade científica, participação em questões sociais, criatividade e autonomia. A pesquisa em si permitiu a participação ativa dos educandos na propagação dos conhecimentos, modificando o modelo comum de orientação sexual visto nas escolas a partir de profissionais da saúde ou pelos próprios professores.

Acredita-se que faz parte do papel do professor permitir a participação dos alunos da construção de seu próprio aprendizado, tornando o ensinar e o aprender um processo dinâmico de organização de ações significativas. Entende-se este movimento da ação executada, refletida e recriada pelo sujeito como o ponto-chave da teoria construtivista, 
o que torna fundamental o acesso consciente dos docentes às implicações dessa concepção para a aprendizagem (11).

A possibilidade de elaborar conteúdos diferenciados e participativos para educação sexual é visível e torna-se claro, nesta investigação, o despertar dos educandos para a participação nos conhecimentos que transformam as aulas em um ambiente de aprendizagem ativa e significativa.

Ademais, é necessária uma reflexão acerca do trabalho interdisciplinar neste ensino. É possível observar várias disciplinas que condizem com as atividades trabalhadas neste projeto, como português, artes, educação física, entre outros. Contudo, o peso do trabalho de sexualidade ainda recai sobre o professor de Biologia/Ciências. Espera-se que as práticas presentes neste projeto apontem possibilidades para as diversas disciplinas trabalharem em conjunto esta temática tão importante na formação dos indivíduos.

\section{Referências bibliográficas}

1. Souza LM, Gomes LMRL, Oliveira JS. Direitos sexuais e reprodutivos: influências dos materiais educativos impressos no processo de educação em sexualidade. Saúde em Debate 2015; 39(106): 683693.

2. Costa LDA. Sexualidade na adolescência. Trabalho de Conclusão de Curso [Monografia]. Especialização em saúde para professores do ensino fundamental e médio. Universidade Federal do Paraná. Curitiba, 2011.

3. Beraldo FNDM. Sexualidade e escola: espaço de intervenção. Psicologia escolar e educacional 2003; 7(1): 103-104.

4. Brasil. Orientação Sexual. [internet] Ministério da Educação e Cultura. [atualizado em 1995; citado em 01 de Junho de 2017]. Disponível em: http://portal.mec.gov.br/seb/arquivos/pdf/livro102.pdf

5. Brasil. Base Nacional Comum Curricular. [internet] Ministério da Educação e Cultura. [atualizado em 2017; citado em 15 de Agosto de 2017]. Disponível em: http://basenacionalcomum.mec.gov.br/images/pdf/1_BNCC-Final_Introducao.pdf

6. Sales SR, Paraíso, MA. O Jovem Macho e a Jovem Difícil: governo da sexualidade no currículo. Educação \& Realidade 2013; 38(2): 603-625.

7. Figueiró MND. A educação sexual presente nos relacionamentos cotidianos. Educação Sexual: em busca de mudanças. Londrina: Universidade Estadual de Londrina 2009; 63-104.

8. Altmann H. Orientação sexual nos parâmetros curriculares nacionais. Revista Estudos Feministas 2001; 9(2): 575- 585.

9. Yazlle, MEHD. Gravidez na adolescência. Revista Brasileira de Ginecologia e Obstetrícia 2006; 28(8): 443-445.

10. Andres SS, Jaeger AA, Goellner SV. Educar para a diversidade: gênero e sexualidade segundo a percepção de estudantes e supervisoras do Programa Institucional de Bolsa de Iniciação à Docência (UFSM). Journal of Physical Education 2015; 26(2): 167-179.

11. Souza S, Franco VS. Geometria na educação infantil: da manipulação empirista ao concreto piagetiano. Ciência \& Educação (Bauru) 2012; 18 (4): 951-964.

12. Candau VM. A didática em questão. 33º ed. Petrópolis, RJ: Vozes, 2012.

13. Demo P. Educar pela pesquisa. $7^{\mathrm{a}}$ ed. Campinas: Autores Associados, 2005.

14. Parafernalha. Garota do Carnaval. [vídeo] [atualizado em 2015; citado em 30 de Agosto de 2017]. Disponível em: https://www.youtube.com/watch?v=a5jVKEAIIs4

15. Cineluz Produções. Meninas. [vídeo] [atualizado em 2015; citado em 30 de Agosto de 2017]. Disponível em: https://www.youtube.com/watch?v=XZIebR6hrgM

16. Conselho Nacional de Saúde. Comissão Nacional De Ética Em Pesquisa. Resolução No 510, de 07 de Abril de 2016. Publicada no DOU no 98, terça-feira, 24 de maio de 2016 - seção 1, páginas 44, 45, 46.

17. Jardim DP, Brêtas JDS. Orientação sexual na escola: a concepção dos professores de Jandira-SP. Rev Bras Enferm. 2006; 59(2): 157-62. 
18. Silva ADSN, Silva BLCN, Júnior S, Silva, MCFD, Guerreiro JF, Sousa, ADSCD. Início da vida sexual em adolescentes escolares: um estudo transversal sobre comportamento sexual de risco em Abaetetuba, Estado do Pará, Brasil. Revista Pan-Amazônica de Saúde 2015; 6(3): 27-34.

19. Amazarray MR, Koller SH. Alguns aspectos observados no desenvolvimento de crianças vítimas de abuso sexual. Psicologia: reflexão e crítica 1998; 11 (3): 559-578.

20. Loyola MA. Cinquenta anos de anticoncepção hormonal: a mulher e a pílula. ComCiência, 2010; (119), 0-0.

21. Dias ACG, Gomes WB. Conversas sobre sexualidade na família e gravidez na adolescência: a percepção dos pais. Estudos de psicologia (Natal) 1999; 4(1): 79-106.

22. Costa ER, Oliveira, KE. A sexualidade segundo a teoria psicanalítica freudiana e o papel dos pais neste processo. Itinerarius Reflectionis 2012; 7(1): 1-17.

23. Hartmann, ÂM, Zimmermann, E. Feira de ciências: a interdisciplinaridade e a contextualização em produções de estudantes de ensino médio. Anais do VII Encontro Nacional de Pesquisa em Educação em Ciências-ENPEC; Florianópolis: ABRAPEC. 2009.

24. Vasconcelos, SD; Silva, MF; Lima, KEC. Uma experiência participante de acompanhamento de uma Feira de Ciências em uma escola pública da Zona Rural de Pernambuco. In VIII Encontro Nacional de Pesquisa em Educação em Ciências (VIII ENPEC) \& I Congresso Iberoamericano de Investigacion en Enseñanza de las Ciencias, UNICAMP-Campinas. 2011. 


\section{Material suplementar \\ Questionário Sexualidade e Gravidez na Adolescência}

- Feminino

- Masculino

1 - Você já teve relação sexual? ( ) Sim ( ) Não

2 - Com qual idade?

3 - Você usa os métodos contraceptivos? ( ) Sim ( ) Não

4 - Qual destes métodos você usa/já usou?

( ) Camisinha

( ) Pílula anticoncepcional

( ) Pílula do dia seguinte

( ) Injeção anticoncepcional

( ) Camisinha feminina

( ) Outros:

5 - Você possui filhos? ( ) Sim ( ) Não. Quantos filhos? Quantos anos você tinha quando o teve?

6 - Quais fontes de informação você utiliza para se informar a respeito de sexualidade?

( ) Televisão

( ) Internet

( ) Pai/Mãe

( ) Professores

( ) Amigos

( ) Livros, revistas e/ou panfletos

( ) Médicos

( ) Outros:

7 - Você sabe o que é DST? ( ) Sim （ ） Não. Se sim, cite um exemplo.

8 - Qual a função dos testículos?

9 - Qual a função do útero?

10 - Deixe aqui sua dúvida sobre sexualidade. 